\title{
Studi Pengaruh Jarak Antar Bilah Panel Difuseer Berbahan Kayu Terhadap Pola Hamburan dan Koefisien Absorbsi
}

\author{
Novanto Adisasmita Kusuma, Suyatno dan Susilo Indrawati \\ Departemen Fisika, Fakultas Ilmu Alam, Institut Teknologi Sepuluh Nopember (ITS) \\ e-mail:novanto.adi@gmail.com
}

\begin{abstract}
Abstrak-Dalam ruangan sering dijumpai panel dengan bentuk unik yang biasanya menempel di dinding, atap dan digantung. Panel tersebut sering dikenal dengan material akustik yang berfungsi sebagai kontrol akustik ruang : absorbsi dan refleksi bunyi. Sifat absorbsi dan refleksi menjadi sangat penting dalam mengatasi cacat akustik. Pada penelitian dibuat panel berbahan kayu dengan variasi jarak dan lebar antar bilah $2 \mathrm{~cm}, 4 \mathrm{~cm}, 6 \mathrm{~cm}$, $8 \mathrm{~cm}$ dan $10 \mathrm{~cm}$. Parameter yang diukur pada penelitian ini antara lain pola hamburan dan koefisien absorbsi. Dari hasil pengukuran, perhitungan dan analisa data diperoleh nilai koefisien absorbsi panel dengan jarak $4 \mathrm{~cm}$ memiliki nilai 0,49 pada frekuensi $125 \mathrm{~Hz}$. Nilai alfa pada panel $2 \mathrm{~cm}$ dengan frekuensi $125 \mathrm{~Hz}$ sebesar 0,18. Nilai tersebut lebih kecil dibandingkan dengan panel yang lainnya, karena bunyi mampu melewati celah yang lebih sempit. Panel dengan variasi jarak $6 \mathrm{~cm}$, $8 \mathrm{~cm}$ dan $10 \mathrm{~cm}$ memiliki nilai alfa dan pola hamburan yang sama. Panel dengan variasai jarak $8 \mathrm{~cm}$ dan $10 \mathrm{~cm}$ memiliki pola hamburan yang merata untuk semua frekuensi.
\end{abstract}

Kata Kunci-Material Akustik, Koefisien Alfa, Kayu, Pola Hamburan.

\section{PENDAHULUAN}

$\mathrm{R}$ ANCANGAN arsitektur bangunan pada dinding tembok dan langit-langit dilapisi dengan material yang berbentuk unik dan menarik. Bentuk yang unik dan menarik pada dinding tersebut memiliki pola yang cenderung rapi. Material yang digunakan biasanya terdiri dari material yang padat dan keras. Dalam penggunaannya material yang memiliki bentuk unik dapat membuat ruang atau gedung berasa megah dan memiliki nilai estetika yang bagus. Namun disamping itu material yang digunakan tadi membutuhkan pengujian terlebih dahulu tetapi jika tidak dilakukan pengujian akan menimbulkan masalah baru. Salah satu permasalahannya adalah gema. Salah satu material yang bisa mengatasi gema adalah difuser karena selain dapat menghamburkan bunyi juga tidak menghilangkan energi bunyi [1].

Bentuk difuser yang sederhana yaitu 10101010 terdiri dari kedalaman yang sama yaitu pada penelitian yang dilakukan oleh Farid (2011). Penelitian sebelumnya hanya memakai satu variasi jarak dengan kedalam yang sama. Kesimpulan dari penelitian yang dilakukan diantaranya koefisien hamburan panel memiliki nilai yang cukup baik kecuali pada frekuensi $2000 \mathrm{~Hz}$ dan nilai koefisien hamburan memiliki nilai positif untuk semua sudut [2].

Pada penelitian yang saya lakukan variasi jarak yang dipakai pada panel lebih banyak. Pada penelitian ini akan dilakukan studi tentang pengaruh jarak antar bilah panel terhadap

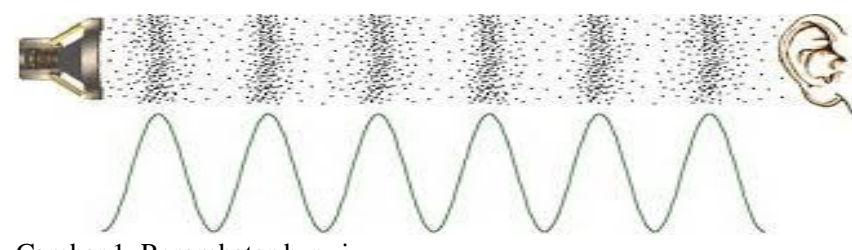

Gambar 1. Perambatan bunyi.

koefisien absorbsi dan pola hamburan. Material yang dipakai pada penelitian terdiri dari kayu berukuran $2 \times 3 \mathrm{~cm}$ dengan panjang 2,5 $\mathrm{m}$ untuk di lakukan pengujian koefisien absorbsi dan pola hamburan.

Bunyi secara harafiah dapat diartikan sebagai sesutau yang kita dengar. Bunyi merupakan hasil getaran dari partikelpartikel yang ada di udara dan energi yang terkndung dalam bunyi dapat meningkat secara cepat dan dapat menempuh jarak yang sangat jauh.

Perambatan bunyimelalui medium yang memiliki massa dan elastisitas, melalui mekanisme rapatan dan renggangan partikel-partikel medium di udara, partikel-partikel udara meneruskan gelombang bunyi tidak berubah posisi normalnya, tetapi hanya bergeser di posisi setimbangnya. Ruang gerak tempat bunyi disebut medan bunyi. Dalam medan bunyi partikel-partikel pada medium bunyi menunjukkan gerakan bolak-balik disekitar posisisetimbangnya. Gerakan bolak-balik inilah yang menyebabkan terjadinya rambatan gelombang. Peristiwa rambatan bunyi dapat dilihat pada Gambar 1 .

Waktu dengung adalah waktu yang dibutuhkan bunyi untuk tetap terdengar dalam sebuah medium (ruang) setelah bunyi as linya tidak ada (mati). Akibatnya dapat memperkuat dan memperjelas bunyi asli. Waktu dengung identik dengan waktu yang dibutuhkan untuk menurunkan sound pressure level sebesar $60 \mathrm{~dB}$ sejak bunyi tersebut berhenti. Dengung dapat terjadi karena adanya pantulan dari mateial yang ada didalam ruang.

Elemen absorber biasanya digunakan apabila ada keinginan untuk mengurangi energi suara di dalam ruangan, atau dengan kata lain apabila tidak diinginkan adanya energi suara yang dikembalikan ke ruang secara berlebihan. Efek penggunaan elemen ini adalah berkurangnya Waktu Dengung ruang (reverberation time). Ciri utama elemen ini adalah secara fisik permukaannya lunak/berpori atau keras tetapimemiliki bukaan (lubang) yang menghubungkan udara dalam ruang dengan material lunak/berpori dibalik bukaannya, dan mengambil banyak energi gelombang suara yang datang ke permukaannya. Khusus untuk frekuensi rendah, elemen ini dapat berupa pelat tipis dengan ruang udara atau bahan lunak dibelakangnya. 


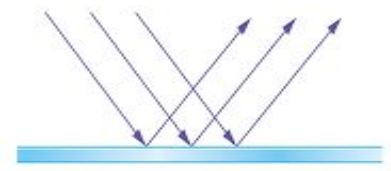

(a) Specular reflection

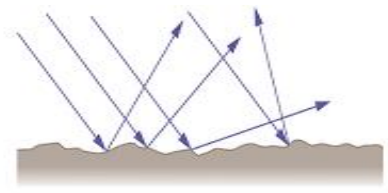

(b) Diffuse reflection
Gambar 2. Peristiwa pantulan spekular dan peristiwa hamburan.
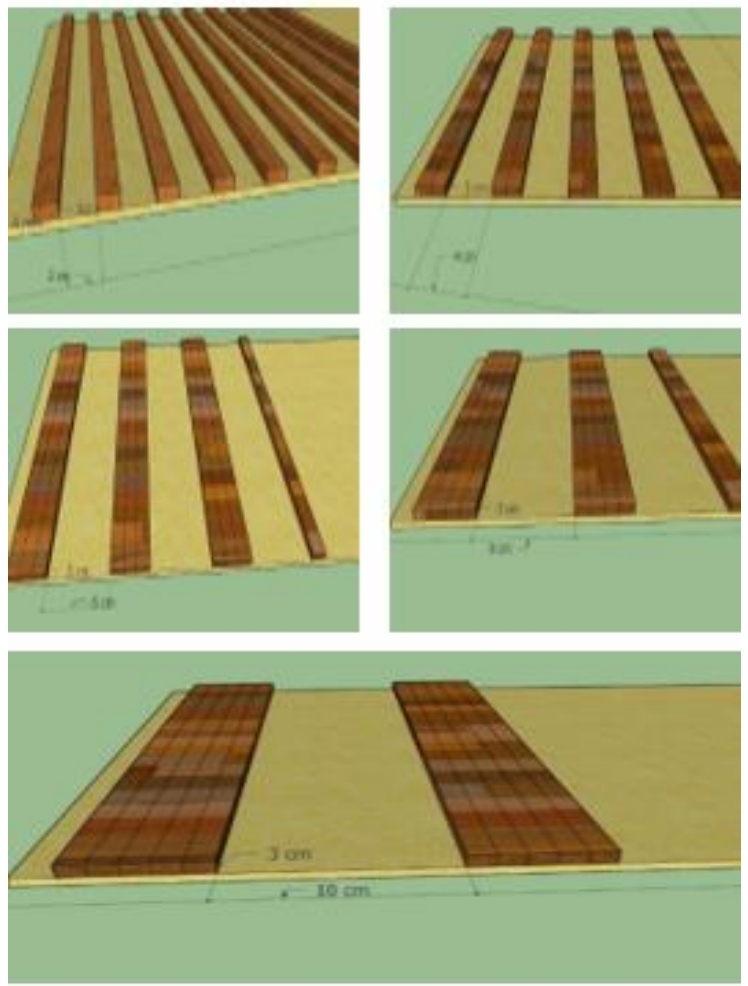

Gambar 3. Panel.

Difraksi adalah peristiwa pelenturan atau pembelokan arah gelombang ketika melewati celah, yang dapat terjadi apabila panjang gelombang bunyi datang lebih besar dibandingkan dengan dimensi penghalang atau celah.

Peristiwa difraksi ini juga dapat terjadi pada gelombang yang mengalami refleksi yang dikenal dengan peristiwa hamburan. Suatu bunyi yang mengenai permukaan bidang, akan memantu 1 ke satu arah sesuai dengan hukum snellius yang dinamakan dengan pantulan spekular. Sedangkan pada peristiwa hamburan, gelombang bunyi yang mengenai suatu bidang, dia akan memantul ke segala arah.

Peristiwa pantulan spekular pada Gambar 2.a terjadi jika bunyi mengenai permukaan halus atau rata. Jika bunyi mengenai permukaan halus atau rata dan panjang gelombang bunyi lebih kecil dari lebar permukaan, maka bunyi akan dipantulkan dengan sudut datang sama dengan sudut pantul. Sebaliknya peristiwa hamburan seperti pada Gambar 2.b terjadi jika bunyi mengenai permukaan kasar atau tidak rata. Jika bunyi mengenai permukaan kasar atau tidak rata dan panjang gelombang bunyi lebih besar dari lebar celah maka bunyi akan dipantulkan dengan sudut pantulan yang tidak beraturan (acak).

Nilai dari SPL gelombang bunyi yang terhambur atau dipantulkan oleh panel dapat dicari dengan persamaan seperti berikut :

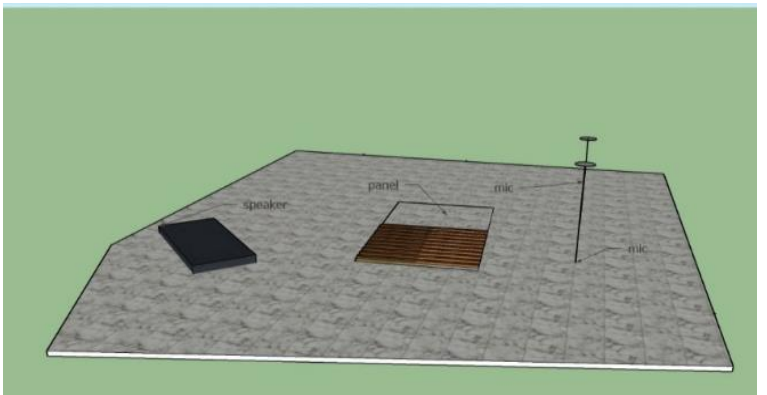

Gambar 4. Pengukuran koefisien absorbsi.

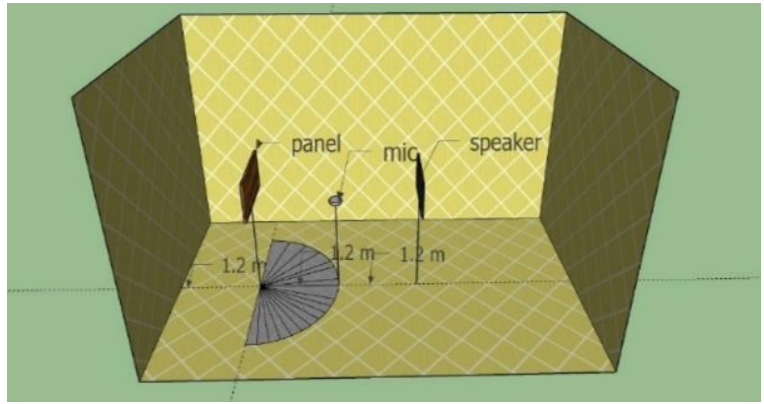

Gambar 5. Pengukuran pola hamburan.

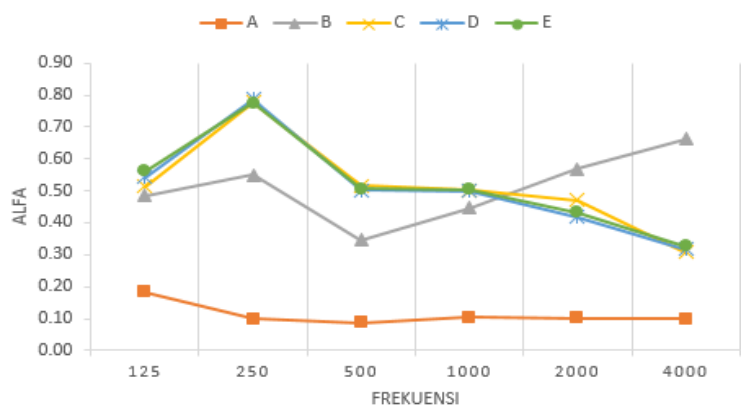

Gambar 6. Grafik koefisien absorbsi.

$$
\begin{aligned}
& \text { SPLSC }=\text { SPLDF }- \text { SPLTD } \\
& \text { SPLDF }=10 \log \left[\frac{P_{D F}}{P_{A C}}\right]^{2} \\
& S P L T D=10 \log \left[\frac{P_{T D}}{P_{A C}}\right]^{2} \\
& P_{s c}^{2}=P_{a c}^{2}\left[\left(10^{\frac{S P L D F}{10}}\right)-\left(10^{\frac{S P L T D}{10}}\right)\right]
\end{aligned}
$$

Maka Spl gelombang yang terhambur (Spl Scattering)

$$
\text { SPLsC }=10 \log \left[\frac{P_{s c}}{P_{A C}}\right]^{2}
$$

Maka SPL gelombang bunyi yang terhambur (SPLscattering) menggunak persamaan :

\section{METODOLOGI}

\section{A. Pembuatan Panel}

Pembuatan panel dilakukan dengan menggunakan balok kayu yang berukuran $2 \times 3 \mathrm{~cm}$ dan mempunyai tinggi $2.5 \mathrm{~m}$. Difusser selanjutnya disusun pada panel triplek dengan dimensi $1.2 \times 2.4 \mathrm{~m}$ dengan tebaltriplek $6 \mathrm{~mm}$. Selanjutnya difuser dibuat 


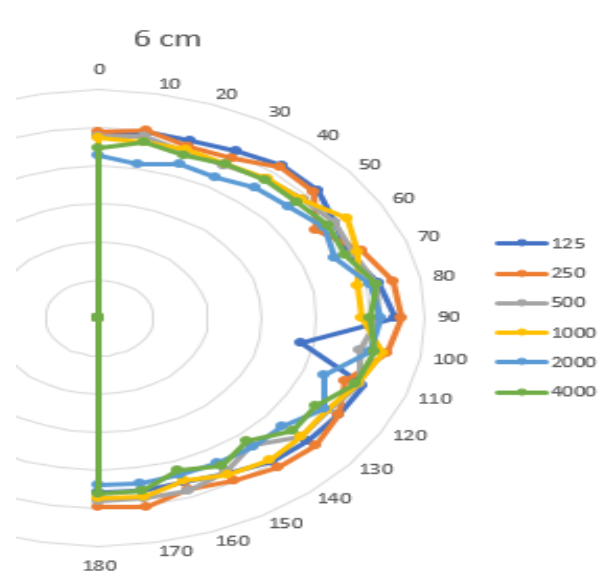

Gambar 7. Pola hamburan panel $6 \mathrm{~cm}$.

dengan menggunakan variasi jarak $2 \mathrm{~cm}, 4 \mathrm{~cm}, 6 \mathrm{~cm}, 8 \mathrm{~cm}$ dan $10 \mathrm{~cm}$ dengan kedalaman yang sama yaitu sebesar $3 \mathrm{~cm}$ seperti terlihat pada Gambar 3.

\section{B. Pengukuran Koefisien Absorbsi}

Pengambilan data waktu dengung bertujuan untuk mencari koefisien absorbsi bahan. Pengambilan data waktu dengung dilakukan di ruang dengung Laboratorium Akustik Departemen Fisika ITS. Pengambilan data dilakukan pada saat ruangan tidak ada bahan uji, kemudian dilanjutkan pengambilan data waktu dengung saat ruangan diberi bahan uji. Dari pengambilan data akan diperoleh data waktu dengung saat ruangan keadaan kosong dan waktu dengung saat ada bahan uji. Bahan uji yang digunakan berupa variasi jarak $2 \mathrm{~cm}, 4 \mathrm{~cm}, 6 \mathrm{~cm}, 8 \mathrm{~cm}$ dan 10 $\mathrm{cm}$.

Pada Gambar 4. cara pengambilan data koefisien absorbsi yang pertama dilakukukan adalah meletakkan panel pada tengah ruangan. Kemudian dua buah microphone diletakkan pada jarak $1 \mathrm{~m}$ dari panel. Speaker diletakkan menghadap tembok. Pengambilan data dilakukan sebanyak 3 kali untuk masing-masing panel. Perhitungan koefisien absorbsi bahan maka dipakai persamaan waktu dengung seperti persamaan berikut :

Dimana :

$$
\alpha=0,16 \frac{V}{A}\left(\frac{1}{T 2}-\frac{1}{T 1}\right)
$$

$\mathrm{A}=$ adalah luas bahan yang akan $\operatorname{diuji}\left(\mathrm{m}^{2}\right)$

$\alpha=$ koefisien absorpsi

$\mathrm{V}=\operatorname{volume}$ ruang $\left(\mathrm{m}^{3}\right)$

$\mathrm{T}_{2}=$ waktu dengung ruang saat ada bahan uji

$\mathrm{T}_{1}=$ waktu dengung ruang saat tidak ada bahan uji.

\section{Pengukuran Koefisien Hamburan}

Pengukuran pola hamburan bertujuan untuk mencari persebaran SPL pada panel. Untuk melakukan pengambilan data pola hamburan dilakukan pengujian di ruang anechoic laboratorium akustik Departemen FISIKA ITS. Pengujian ini untuk mengambil SPL hamburan. Pengukuran SPL dilakukan setiap $10^{\circ}$ dilakukan mulai sudut $0-180^{\circ}$. Pengukuran dilakukan dengan ruangan dengan keadaan bahan uji triplek kemudian variasi jarak. Pada Gambar 5 menjelaskan cara melakukan pengujian panel untuk pola hamburan.

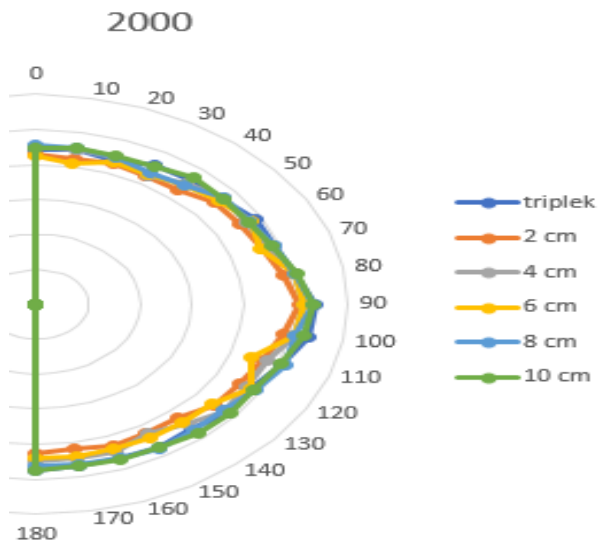

Gambar 8. Pola hamburan panel frekuensi $2000 \mathrm{~Hz}$.

Pada Gambar 5 panel diletakkan di tengah ruang uji, kemudian panel ditempatkan pada jarak 1,2 meter dari dinding belakang lalu microphone diletakkan pada jarak 1,2 meter dari panel. Speaker ditempatkan pada jarak 1.2 meter dari microphone. Metode pengukuran Pola hamburan yang digunakan pada penelitian ini didasarkan pada literatur acoustic absorbers and diffusers karangan Trevor J. Cox.

\section{A. Koefisien Absorbsi}

\section{HASIL}

Pada Gambar 5 dimana koefisien absorbi panel dengan variasi jarak $4 \mathrm{~cm}$ memiliki nilai koefisien absorbsi terbesar pada frekuensi $125 \mathrm{~Hz}$ dan $4000 \mathrm{~Hz}$. Pada frekuensi 250 dan $500 \mathrm{~Hz}$ terjadi penurunan dan kenaikan lagi pada frekuensi $1000 \mathrm{~Hz}$ s ampai $4000 \mathrm{~Hz}$ seperiyang ditunjukkan pada Gambar 6. Hal ini terjadi karena pada frekuensi tinggi absorbsi panel juga tinggi karena pada panel dengan variasi $4 \mathrm{~cm}$ gelombang bunyi yang datang bis a masuk ke dalam celah panel, sedangkan pada frekuensi rendah gelombang bunyi hanya sampai pada permukaan panel tidak bisa masuk ke dalam celah panel.

Pada Gambar 6 nilai koefisien absorbsi pada panel $6 \mathrm{~cm}, 8$ $\mathrm{cm}$ dan $10 \mathrm{~cm}$ mempunyai nilai yang relatif sama. Hal ini disebabkan karena pada frekuensi $125 \mathrm{~Hz}$ panjang gelomabang pada frekuensi tersebut cukup panjang sehingga bunyi yang dirambatkan dalam ruang memiliki daya tekan yang cukup besar kepada panel atau material sehingga menyebabkan banyak gelombang bunyi yang diserap oleh material uji daripada yang dipantulkan. Koefisien absorpsi pada frekuensi panel dengan konfigurasi $4 \mathrm{~cm}$ menurun pada frekuensi $500 \mathrm{~Hz}$ disebakan amplitudo gelombang pantul meningkat, sehingga gelombang bunyi yang datang melemah mengakibatkan amplitudo tekanan minimumnya meningkat, mengakibatkan koefisien absorbsimenurun sehingga lebih banyak bunyi yang dipantulkan daripada yang diserap. Karena panel dengan variasi $6 \mathrm{~cm}, 8 \mathrm{~cm}$ dan $10 \mathrm{~cm}$ pada frekuensi rendah gelombang bunyi hamya sampai pada pada permukaan panel tetapi tidak bisa melewati celah tetapi pada frekuensi tinggi gelombang bunyi mampu melewati celah sehingga mengakibatkan banyak gelombang bunyiyang diserap daripada dipantulkan.

\section{B. Pola Hamburan}

Pada Gambar 6 merupakan pola hamburan pada panel dengan variasi jarak $6 \mathrm{~cm}$ dengan menggunakan frekuensi 125 
$\mathrm{Hz}$ sampai $4000 \mathrm{~Hz}$. Pada panel $6 \mathrm{~cm}$ terdapat beberapa penurunan pola hamburan yang cukup signifikan pada frekuensi $125 \mathrm{~Hz}$ pada $100^{\circ}$ dan frekuensi $2000 \mathrm{~Hz}$ pada sudut $120^{\circ}$.

Pada Gambar 7 terlihat pola hamburan pada panel dengan variasi jarak $6 \mathrm{~cm}$ terdapat penurunan yang cukup signifikan pada sudu $100^{\circ}$ pada frekuensi $125 \mathrm{~Hz}$. Hal ini karena bunyi dari speaker memiliki arah yang spekular dan pada frekuensi rendah bunyidari speaker terpantuldidalam panelhal ini terjadi karena panjang gelombang bunyi lebih besar dari lebar celah sehingga bunyi akan terdifraksi (dibelokkan) sehingga bunyi yang tertangkap oleh mikrophone pada sudut-sudut tertentu memiliki nilai yang cukup kecil. Karena pada panel dengan jarak $4 \mathrm{~cm}$ memiliki bentuk yang tidak rata aatau kasar maka bunyi yang mengenai permukaan panel yang tidak rata atau kasar maka bunyi akan dipantulkan secara acak (tidak beraturan).

Pada Gambar 8 merupakan perbandingan antara panel dengan variasi jarak $2 \mathrm{~cm}, 4 \mathrm{~cm}, 6 \mathrm{~cm}, 8 \mathrm{~cm}$ dan $10 \mathrm{~cm}$ dengan panel triplek pada frekuensi $2000 \mathrm{~Hz}$. Hal ini disebabkan karena pada frekuensi tinggi, bunyi yang mengenai panel tidak hanya sampai pada permukaan panel tetapi juga bisa masuk ke dalam celah panel sehingga bunyi yang terpantul di dalam celah panel bisa keluar dari celah panel sehingga bunyi yang terekam oleh mikrophone memilki nilai yang merata untuksemua sudut. Hal ini sesuai dengan hukum snellius dimana sudut datang sama dengan sudut pantul.

\section{KESIMPULAN}

Berdasarkan hasil pengukuran dan perhitungan maka didapatkan kesimpulan. Nilai koefisien absorbsi pada panel dengan variasi $2 \mathrm{~cm}$ dengan frekuensi $125 \mathrm{~Hz}$ memiliki nilai 0,18 , sedangkan panel dengan variasi $4 \mathrm{~cm}$ dengan frekuensi $125 \mathrm{~Hz}$ memiliki nilai 0,49 . Pada panel $6 \mathrm{~cm}, 8 \mathrm{~cm}$ dan $10 \mathrm{~cm}$ memiliki nilai yang sama pada frekuensi $125 \mathrm{~Hz}$. Sedangkan pola hamburan panel $2 \mathrm{~cm}$ merata pada frekuensi $1000 \mathrm{~Hz}$, pada panel $4 \mathrm{~cm}$ merata pada frekuensi $4000 \mathrm{~Hz}$, pada panel $6 \mathrm{~cm}$ merata pada frekuensi $1000 \mathrm{~Hz}$ dan pola hamburan panel $8 \mathrm{~cm}$ dan $10 \mathrm{~cm}$ meerata untuk semua frekuensi.

\section{DAFTAR PUSTAKA}

[1] P D'Antonio and Cox. Trevor J, Acoustic absorber and diffuser: theory, design and application. London: Spon Press, 2004.

[2] Farid, "Studi awal pengukuran koefisien hamburan diffuser MLS(maximum length sequence) tipe 1101000110,” Surabaya, 2011. 